\section{VOLUNTARIOS: DISCÍPULOS Y CIUDADANOS}

Autor: Pedro Coduras. Sacerdote jesuita aragonés, psicólogo, ha colaborado con el Voluntariado de Marginación Claver, y actualmente es director del Proyecto Hombre de Zaragoza.

DOI: https://doi.org/10.52039/seminarios.v47i162.930
La comunidad cristiana siempre ha hecho el esfuerzo de responder al ser discípulo y ciudadano. En el voluntariado social encuentra un cauce de expresión. Bllo nos exige estar abierto a realidades distintas de nuestro "ambiente natural". estableciendo dinámicas de "inclusión" y dando protagonismo a las personas que atienden. Sus pilares, la relación con el otro y el encuentro con el Otro. El voluntariado social se radicaliza desde el discipulado cristiano, respuesta al amor incondicional del Padre.

\title{
INTRODUCCIÓN
}

Con el título de "Voluntarios: discípulos y ciudadanos" queremos expresar la tensión en la que todo/a cristiano/a se encuentra en nuestra sociedad. Seguir a Jesús de Nazaret formando parte de la comunidad cristiana y, a la vez, colaborar en la construcción de la sociedad en tanto que ciudadanos, son las dos tareas básicas de todo/a creyente en el Dios de Jesús.

Esta tensión lleva consigo en unas ocasiones rupturas y, en otras, subrayados de un polo o de otro. Si nos resulta difícil admitir cualquier tensión existencial, cuánto más ésta, que pone en cuestión algo tan esencial al ser humano como es su identidad. Desde los diferentes acen-

\footnotetext{
- Tomado de Cristianisme i Justícia, n 68. Barcelona.
} 
tos que encontramos en el Nuevo Testamento hasta la evolución doctrinal expresada en los documentos de la Iglesia, se hace patente el continuo esfuerzo de la comunidad cristiana por responder honestamente y en profundidad a esta doble pertenencia: ser discípulos y ciudadanos.

\section{Tesis de este artículo}

Voluntariado, vía para simultanear ser ciudadano y ser cristiano
La tesis de este artículo es que el voluntariado social permite, como muy pocas actividades humanas, que la persona realice simultáneamente su identidad como ciudadano/a y como cristiano/a.

No se trata de hacer un análisis del voluntariado en España, ni de una reflexión filosófica o sociológica sobre este fenómeno social. El lector/a que busque más información en esta línea puede consultar las obras de García Roca, Wuthnow y los Cuadernos de la Plataforma para la Promoción del Voluntariado. En las notas encontrará el lector/a las referencias.

Este cuaderno -ayudado por dichos estudios- pretende aportar alguna pista para la reflexión creyente sobre el voluntariado. Para ello, definiremos, en primer lugar, de qué voluntariado estamos hablando y cuáles son sus características, en cuanto a su participación en la acción social; analizaremos, en segundo lugar, qué tipo de voluntariado surge de la motivación cristiana y cómo se relaciona esa actividad voluntaria con el seguimiento de Jesús; y, por último, sugeriremos las características del voluntariado social vivido desde la fe. También, su contribución como ciudadanía cristiana a un ideal de sociedad basado en la inclusión y la participación, en la justicia y la fraternidad.

Quisiéramos acompañar la experiencia de multitud de cristianas y cristianos que ofrecen parte de su tiempo y energías al servicio del otro, del excluido.

\section{EL VOLUNTARIO EN TANTO QUE CIUDADANO}

La palabra "voluntariado" define muy distintas realidades. Ello sugiere la gran riqueza de la participación humana, pero esconde el riesgo de defender algunas actividades y grupos de intereses que no responden a lo que aquí vamos a considerar como voluntariado. Vea- 
mos tres definiciones, procedentes de ámbitos diversos, para constatar esa diversidad:

- "En la resolución adoptada por el Parlamento Europeo en diciembre de 1983 reencontramos las cuatro características de base: el voluntariado no es obligatorio, es interesante para la sociedad, normalmente no remunerado, y se realiza en un cuadro más o menos organizado ${ }^{1 "}$.

- "Sería voluntario el que actúa desinteresadamente, con responsabilidad, sin remuneración económica, en una acción realizada en beneficio de la comunidad, que obedece a un programa de acción con voluntad de servir; es una actividad solidaria y social, el trabajo del voluntario no es su ocupación laboral habitual, es una decisión responsable que proviene de un proceso de sensibilización y concienciación, respeta plenamente al individuo o individuos a quienes dirige su actividad y puede trabajar de forma aislada, aunque por lo general actúa en grupo $2 "$ ".

- "El voluntariado social acaba entendiéndose como un servicio gratuito y desinteresado que nace de la triple conquista de la ciudadanía: como un ejercicio de la autonomía individual, de la participación social y de la solidaridad para con los últimos 3 ".

Progresivamente, las tres definiciones van limitando el ámbito del término. La primera trata de abarcar cualquier acción voluntaria. Podría incluir a colegios profesionales, grupos de interés, etc. La última restringe el voluntariado a lo social, con claros tintes de compromiso socio-político y de inclusión. En este cuaderno, consideramos esta última definición como la que mejor describe el tipo de acción voluntaria que se deriva del discipulado cristiano.

Es importante darse cuenta de que esta concepción de voluntariado no habla de altruismo -y mucho menos de heroicidad- sino que fundamenta la acción voluntaria en la puesta en práctica de la ciuda-

${ }^{1}$ BOLLAERTS, Liliane. El Voluntariado en Europa. Madrid: Cruz Roja Española, Departamento de Voluntariado, 1987. En Conferencia Nacional sobre Voluntariado, Sevi1la, 8-10 mayo 1986, p. 17.

${ }^{2}$ CALO, José Ramón, ¿Qué es ser voluntario? Madrid: Plataforma para la Promoción del Voluntariado, 1990. En Cuadernos de la Plataforma, 2, p. 14.

${ }^{3}$ GARCÍA ROCA, Joaquín. Solidaridad y Voluntariado. Santander. Sal Terrae, 1994, p. 62.

Acción voluntaria, derivada del discipulado cristiano, la de ámbito social 
danía. Ser voluntario social, para García Roca, es, simplemente, la consecuencia de tomarse en serio la condición de ciudadano/a.

Evidentemente, se está hablando de una ciudadanía responsable e interesada por la justicia. Por desgracia, este modo de entender la ciudadanía no es mayoritaria en nuestra sociedad. Pero esto no implica que sólo se pueda hacer la opción por los pobres (o la "solidaridad para con los últimos", tal como se expresa en la definición anterior) desde la llamada al discipulado, al seguimiento de Jesús.

Conviene aclarar desde el principio que al considerar la motivación cristiana y sus consecuencias en la acción voluntaria no estamos definiendo un nuevo tipo de voluntariado que sin la fe sería imposible. Como veremos más adelante, "cristiano" califica la acción voluntaria, es decir, le ofrece una motivación, una llamada a la radicalidad y un ámbito comunitario. Éste posibilita la razonabilidad y el mantenimiento de la utopía exigido por el voluntariado social tal como aquí lo definimos.

Pero, volvamos al voluntariado como ciudadanía para subrayar sus características. Posteriormente lo analizaremos desde la visión creyente. Podemos definirlo a través de tres acciones que lo caracterizan.

\section{DESCUBRIR NUESTRA DIVERSIDAD}

\section{SALIR DEL CÍRCULO DE NUESTROS AMIGOS Y NIVEL SOCIAL}

La construcción de una sociedad democrática exige, según Robert

Sensibili-

dad para

percibir la situación

social Bellah el "tener cuidado". Esto supone una sensibilidad creciente para percibir la situación social, la recuperación de la idea de bien común y un compromiso respetuoso y crítico con las instituciones sociales ${ }^{4}$. Esta nueva percepción de la sociedad o "comprensión ilustrada" (enlightened understanding) que requiere de una mayor información y exposición a la realidad se considera uno de los elementos básicos del proceso democrático5.

\footnotetext{
${ }^{4}$ BELLAH, Robert, (et al.) The Good Society. New York: Vintage Books, 1992, p. 254.

5 Cf. DAHL, Robert A. Democracy and Its Critics. New Haven, Yale University Press, 1989, p. 111-112.
} 
Para ello, es necesario estar abierto a otras realidades sociales distintas a la del grupo social al que pertenecemos. Hay que salir del "círculo reducido" de nuestros familiares y amigos, de nuestro nivel social y cultural. No basta, por tanto, con la voluntariedad de nuestra acción; ésta ha de atravesar las fronteras sociales que nos dividen y separan.

El voluntariado social cruza estas fronteras y, al hacerlo, descubre al resto de la sociedad la existencia de vidas humanas que necesitan y merecen ser tenidas en cuenta. Es en el contacto directo con las personas excluidas donde el voluntario descubre el primer impulso de su acción: la compasión, no como sentimiento de pena y conmiseración, sino viendo la realidad con los ojos del corazón.

No es posible quedar indiferente ante el dolor y la rabia que produce la exclusión. Por ello, una de las primeras tareas del voluntariado social es relatar las historias, casi olvidadas, de sufrimiento y lucha, de negación de dignidad y de esperanza que encuentra en su servicio. Con ello, permite que la compasión atraviese e impregne el lenguaje utilitarista e individualista de nuestra cultura.

Gracias a esta implicación con las víctimas del sistema desde el nivel personal y local, puede el voluntariado ser fermento de una acción social que, sin olvidar la justicia y sus mediaciones, aporte la misericordia, generosidad y gratuidad que sólo nacen del encuentro y la relación humanas.

De aquí surge la primera pregunta

- ¿Comporta nuestra acción voluntaria un estilo de trabajo que asuma el riesgo de salir de lo conocido, del "círculo reducido" de iguales (o de los "casi-iguales")?

Este estilo de trabajo implica una pérdida de seguridad; una necesaria apertura a aprender, conocer y valorar modos distintos de vida y relación; un "dejarse afectar" por la realidad con la que nos encontramos (dolor, resentimiento, internalización de la exclusión, agresividad, etc). Que nadie se asuste; para cumplir esta primera característica no Esto implica pérdida de seguridad

Atravesar

la frontera de nuestro círculo reducido

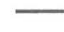




\section{REDEFINIR EL BIEN COMÚN}

\section{PARA LOS QUE HAN SIDO APARTADOS DE LA SOCIE- DAD, LA CONCEPCIÓN DE BIEN COMÚN DIFIERE DE LA QUE TIENE LA "SOCIEDAD ESTABLECIDA"}

El voluntariado, entendido como ciudadanía responsable e inclusiva, pretende redefinir la sociedad en su conjunto. Bien Común es aquello que, entre todos, consideramos como objetivo de nuestra convivencia, el ideal al que tendemos.

No cabe duda de que dicho ideal es entendido de distinta manera por los diversos grupos que integran la sociedad. Tampoco, que es un ideal ajeno e inaccesible a grandes porcentajes de la población, cuyo derecho a participar socialmente es teórico y, en la práctica, no reconocido.

Los voluntarios pertenecen, mayoritariamente, a sectores sociales

Dinámicas de inclusión y recuperación de dignidad que pueden ejercer sus derechos ciudadanos y participar en la definición del ideal de sociedad. De ahí que, a partir de la acción voluntaria sea preciso generar dinámicas de inclusión ${ }^{6}$ y de recuperación de dignidad, que permitan la participación de los excluidos del sistema en la redefinición de dicho ideal.

Un voluntariado que se aleja definitivamente de concepciones "benéficas" y paternalistas

Se trata de establecer un diálogo; no el monólogo característico de la beneficencia clásica. Este es uno de los puntos clave de legitimidad del voluntariado, donde se juega su credibilidad como agente social.

Trabajos como la rehabilitación de personas dependientes, la asistencia a colectivos en precariedad económica o de otro tipo, etc, han de llevar a la "inserción" o inclusión de estas personas en el conjunto de la sociedad. Hemos de trabajar por la recuperación de sus derechos de participación política, económica y social, tanto en los recursos como en las obligaciones de la comunidad a la que, por derecho y dignidad humana, pertenecen.

6 Para un análisis de la importancia de la "Inclusión" en la profundización y reforma de nuestra democracia occidental, Cf. DAHL, R. Op.cit.p. 119-134 
Para evitar el peligro de convertirse en cómplice de la injusticia y la exclusión al tapar meramente con un parche las consecuencias de éstas, el voluntariado social ha de manifestar en sus objetivos y en su metodología un elemento clave: el "dar protagonismo" a las personas que atiende. No se trata de sustituir la presencia y la voz del otro, sino de recrear el ejercicio de la mediación con una "presencia ligera que devuelva a las personas carenciadas su propio protagonismo 7 ".

Esto que en teoría puede parecer "de cajón", en la práctica no lo es tanto. No es fácil renunciar a nuestros intereses (en primer lugar, al de "redentores") ni abandonar nuestro individualismo ${ }^{8}$. Y aún es más difícil creer que ciertos colectivos marginales puedan tener una palabra que decir sobre ellos mismos (deficientes profundos, niños, extranjeros, etc.) o, al menos, tener "la" palabra apropiada, dadas sus características culturales, físicas o psíquicas. Como subraya Toni Catalá, "es impresionante constatar cómo no se soporta el que los otros salgan de la periferia asignada para ellos. Muchas pretendidas políticas sociales, lo que hacen es asear los contextos periféricos para que todo siga igual: para que siga cada uno en su sitio".

\section{Apuesta por el "privilegio epistemológico de los pobres"}

Un voluntariado social, como el que aquí definimos, apuesta por el "privilegio epistemológico de los pobres"; esto es: la realidad se ve mejor "desde abajo", "desde afuera" de los límites sociales. Y esto es algo difícil de hacer comprender a quienes no se han dejado afectar por los otros, los ajenos, los distintos; a las personas que reducen su mundo vital al de sus iguales y al de aquellos que están por encima en la escala social. Sin embargo, cualquier voluntario/a social sabe por expe-

Ver la realidad desde fuera de los límites sociales

${ }^{7}$ GARCÍA ROCA, J., op.cit, p. 137.

${ }^{8}$ Las encuestas sobre las motivaciones del voluntariado reflejan no sólo que el individualismo no es incompatible con el servicio sino que la autorrealización es una motivación fuertemente presente a la hora de ayudar a los demás.

${ }^{9}$ CATALÁ, Toni. Salgamos a buscarlo. Notas para una teología y una espiritualidad desde el Cuarto Mundo. Sal Terrae, Santander, 1992. en Aquí y Ahora, 21, p. 17. La crítica de Catalá no se dirige únicamente a las "políticas sociales", también incluye a la lectura "científica" de los milagros de Jesús que permite mantener las fronteras sociales, frente a la práctica incluyente de dichos milagros. 
riencia que hay un lugar y un modo de ver la realidad que amplía la propia visión. Sólo desde esta experiencia se justifica la necesidad de dar voz y protagonismo a los excluidos. Porque si no tuvieran una visión alternativa de la vida ¿para qué darles voz? Sería más práctico continuar decidiendo por ellos qué acciones emprender para resolver sus problemas.

Para aquellos que han sido apartados de la sociedad, la concepción de Bien Común difiere de la que tiene la "sociedad establecida". Cuestiones como raza, sexo y bienestar económico tienen un significado diferente y, sobre todo, reciben un valor distinto. Sólo la inclusión de aquellos que hemos excluido de nuestro sistema puede aliviar a nuestra sociedad de la "ceguera epistemológica" (ciegos a cualquier visión de la realidad que no responda a nuestra cultura e intereses) que nos afecta y que hace inherente al sistema la suplantación, la intolerancia y el miedo.

La segunda pregunta incluye dos cuestiones prácticas cruciales:

- ¿Qué papel juegan en nuestro voluntariado los beneficiarios del mismo? ¿Participan en los órganos de decisión? ¿Tienen algún poder respecto a los objetivos, metodología y evaluación de resultados?

- ¿Ha cambiado nuestra visión de la realidad social a partir del trabajo voluntario y de nuestra relación con las personas afectadas? ¿Qué contribución específica se ha producido? ¿Cómo ha cambiado mi visión de mí mismo, en lo personal y en relación con la realidad entorno?

Respuestas negativas o confusas a las anteriores preguntas nos situarían en el modelo de actuación de los conquistadores en América o del franquismo de nuestra historia reciente. Para los unos, los indios eran seres "menores de edad" incapacitados para saber qué querían y necesitaban. Para el otro, el pueblo español era inmaduro para decidir por sí mismo. Y es que, no sólo la historia se repite, sino que somos capaces de justificar los mismos estilos colonialistas y paternalistas de antaño con argumentos ideológicos tomados de la crítica marxista o de la posmodernidad. 


\section{PROMOVER EL CAMBIO SOCIAL}

\section{VOLUNTARIADO SIGNIFICA NO SÓLO COMPROMISO PERSONAL CON INDIVIDUOS, SINO TAMBIÉN CON ESTRUCTURAS E INSTITUCIONES}

Finalmente, el sector voluntario está compuesto de una compleja red de instituciones y organizaciones. Esto constituye una de las principales aportaciones a la sociedad del llamado "tercer sector", por contraposición al sector público-estatal y al sector mercantil-empresarial.

Las asociaciones de voluntariado actúan como intermediarias entre el Estado y la ciudadanía

Esta red social distribuye el poder en la sociedad de un modo que reafirma el pluralismo político y salvaguarda las libertades de los ciudadanos. Las asociaciones de voluntarios actúan como intermediarias entre el Estado y la ciudadanía, ofreciendo un canal para la participación ciudadana. Ambos papeles (distribución del poder, promoción de la participación) hacen de dichas asociaciones uno de los mejores ejemplos del "principio de subsidiariedad", postulado en el Pensamiento Social Cristiano. Robert Bellah recupera la relevancia de este principio para la sociedad actual cuando afirma que "el principio de subsidiariedad" favorece la cooperación social y la descentralización del poder. Ésta posibilita "un nuevo experimento en democracia participativa' en el lugar de trabajo y la política ${ }^{10 "}$.

Sin embargo, no toda acción voluntaria se implica en un proceso de cambio social: no basta la honradez y la gratuidad; hay que evaluar el trabajo para evitar la legitimación del sistema. Subsidiariedad y complementariedad con las instituciones públicas y sus intervenciones sociales no equivale a "asistencia y apoyo acríticos" por parte del voluntariado. Antes bien, han de proponer nuevas políticas sociales y comprometerse, no sólo de manera personal con individuos, sino también con estructuras e instituciones.

El cambio social dinamizado por el voluntariado social va desde la inclusión en la sociedad y en sus órganos de decisión de los excluidos, a la promoción de un nuevo concepto de justicia, una justicia

Promocionar un nuevo concepto de justicia

10 BELLAH, Robert, op. cit. p. 282. 
"comunitarista". Se trata de una justicia contextual e histórica, que respeta las diferencias, que afirma el valor moral de personas y grupos, que apoya la autonomía y el respeto a sí mismo, que domestica la autoridad y que, finalmente, establece el marco teórico y experiencial para el debate moral en los temas públicos ${ }^{11}$. La inclusión, de la que hemos hablado en el apartado anterior, está en línea con este ideal de justicia. De hecho, la acción voluntaria -en su trabajo de inclusión- supone el respeto por la autonomía de la persona, así como la capacitación para desarrollar todas las características (derechos y deberes) de la ciudadanía. La lucha que las asociaciones de voluntariado despliegan por una igual dignidad y protección se basa en la radical identidad común de todos los hombres y mujeres. Su trabajo lucha contra el estigma moral que clasifica a unas personas como "intrínsecamente" peores que otras.

La pelea por una ciudadanía más amplia e inclusiva no es simplemente algo práctico. Implica un debate ideológico y político, al tiempo que un compromiso personal y una asunción de riesgos. En la búsqueda de una justicia comunitarista, se ha de implicar no sólo el/la voluntario/a, sino también su organización. Los voluntarios sociales contactan con las diversas y ambiguas realidades humanas, que les dan la convicción de una necesaria y continua lucha por la justicia. La red de asociaciones de voluntarios tiene el irrenunciable deber de reflejar estas experiencias concretas, transmitirlas a la sociedad y pedir las medidas sociales y jurídicas que respondan a las necesidades de los más desfavorecidos. La acción voluntaria, si quiere ser ética, no sólo

Compromiso con la justicia social, piedra de toque de credibilidad ha de caminar con las víctimas, sino que ha de tener a su favor la voluntad de cambio ${ }^{12}$. En nuestra sociedad, el compromiso con la justicia social es la piedra de toque de la credibilidad, tanto de las personas voluntarias como de sus instituciones.

La tercera pregunta es consecuencia directa de lo anterior

${ }^{11}$ Una idea tal de justicia requiere una comunidad que la sustente. Para una discusión sobre la relación entre justicia y comunidad, así como sobre la necesaria revisión de nuestra concepción legalista y de "derechos" de justicia. Cf. SELZNICK, Philip. The Moral Commonwealth. Social Theory and the Promise of Community. Berkeley, University of California Press, 1992, cap. 15.

12 GARCÍA ROCA, Joaquín, op. cit. p. 52. 
- ¿Qué objetivos de cambio socio-político persigo yo y la asociación a la que pertenezco? ¿Somos capaces de formular alternativas? ¿Qué lugar ocupa en mi servicio la pertenencia a una asociación?

En el clásico dilema entre justicia y misericordia (recuérdese la célebre cita de Dostoyewsky: "no tenéis ternura, sólo tenéis justicia, por eso sois injustos"), esta pregunta evita el desplazamiento de nuestro servicio al campo de la beneficencia y, por tanto, al papel de "tontos útiles" al sistema. Éste, a la vez que engendra muerte y exclusión, se goza en los gestos heroicos de aquellos que sólo buscan aliviar las consecuencias del mal estructural sin tratar de atajar sus causas.

El compromiso con la justicia y por el cambio social necesita una motivación radical. No corren tiempos fáciles para la ética, para la implicación radical. Hay dos grandes pilares para el altruismo y la acción voluntaria: la relación con el otro y el encuentro con la trascendencia, la divinidad, el Otro. La combinación de ambos da solidez al compromiso radical, aun en tiempos de desencanto. En este apartado nos hemos limitado al voluntariado como expresión de la identidad ciudadana, como acción nacida de la misma identidad humana que, para serlo, requiere abrirse a la relación con el "otro".

Sin negar la fuerza de esta motivación ciudadana, la experiencia cotidiana nos muestra que es difícil asumir los riesgos de cruzar fronteras sociales, implicarse en historias y relaciones cargadas de dolor y confusión, aceptar los cambios que todo ello implica, perder la seguridad de un espacio estable y protegido por los derechos adquiridos al nacer... en definitiva, "vivir en la frontera", como diría J. L. Sampedro.

Se hace necesario un "relato", sí, un relato, una narración existencial que nos permita comprender el porqué de una opción tan irracional a los ojos de cuantos nos rodean y de nuestra propia cultura. Es necesaria una "comunidad de memoria" que ofrezca una tradición, es decir, un modo de ver la realidad que dé sentido al sacrificio, no al heroísmo, sino a los cotidianos y aparentemente inútiles actos de compasión y de lucha por la justicia. Aquí se encuentra nuestra responsabilidad como creyentes, como pueblo que tiene el "regalo de la fe": ser embajadores de confianza en un mundo de sospecha. 


\section{EL VOLUNTARIO EN TANTO QUE DISCÍPULO}

La fe cristiana reclama una nueva identidad para aquellos que han "nacido del agua y del espíritu" (Jn 3,5). ¿Cómo se relaciona esta

Voluntariado social: un modo de vivir la identidad cristiana en el mundo
Ética cristiana es respuesta agradecida nueva identidad con la identidad ciudadana que nos caracteriza como miembros de la sociedad secular? ¿Qué relación tiene esa "nueva identidad" cristiana con el voluntariado del que aquí hablamos? Mi respuesta es doble: por una parte, el voluntariado social es un modo (no el único, pero sí uno de los más privilegiados) de vivir la identidad cristiana en el mundo; por otra, el discipulado cristiano radicaliza el voluntariado social, y con él nuestra ciudadanía, al dotarle de una narrativa de entrega radical al otro. Es una respuesta al amor incondicional del Padre, es decir, la narrativa existencial de Jesús de Nazaret.

\section{DISCÍPULOS QUE RESPONDEN AL "AMOR PRIMERO"}

La comunidad cristiana encuentra la motivación para la "caridad" (amor fraterno, hecho de justicia y misericordia, al estilo de nuestro Dios) en el haber sido amados por Cristo. Es ese amor y no otra cosa (Ley, Tradición, seguridad, etc.) lo que constituye la norma para nuestra moralidad. Por tanto, todas nuestras acciones altruistas, solidarias y compasivas nacen de la gratitud a un "amor primero", inmerecido e impagable.

Esto que puede sonar a "perogrullada" es la clave de cuanto vamos a analizar seguidamente. La radicalidad que hemos planteado hasta ahora sólo puede vivirse desde la respuesta agradecida a un amor que nos ha desbordado. Como afirma P. Jaramillo, "el voluntariado vendría a ser la expresión práctica de entender la propia existencia como don recibido. Quien se entiende a sí mismo desde esa radicalidad creyente, necesariamente expresa ese reconocimiento en una existencia vivida como don ofrecido. Somos don de Dios en orden a ser don para los demás"13.

La ética cristiana no es un compendio de normas y deberes, sino una respuesta agradecida. Ahora bien, no podemos olvidar que Jesús sí

13 JARAMILLO RIVAS, Pedro. El Voluntariado Social: la mística de la gratuidad. Madrid, Cáritas Española, 1993. En Corintios 13, 65, p. 176. 
formuló un único mandamiento, el del amor. Tampoco podemos separarlo de la narrativa (la historia) de Jesús que define este amor y su imperativo para todos nosotros: "amaos como yo os he amado" (Jn 13,34-35). El lavatorio de los pies y la cruz son el modo de entender, contemplar y vivir este mandamiento.

La palabra "cristiano", en su sentido más propio, significa "seguidor de Cristo". En los Evangelios, cuando se habla de seguir a Jesús, sólo se usan dos términos: mathetes (discípulo) y akoloutheuo (siguiendo tras...). El sustantivo "discipulado" como concepto no aparece. Esto refleja la idea práctica que las primeras comunidades tenían del discipulado, como un "camino", un proceso, una práctica, no un status o concepto teórico. Se trata de un proceso en marcha, dinámico, de adhesión y participación con Jesús, el Cristo.

Una última consideración. Sólo una de cada diez veces que la palabra "discípulo" aparece en el Evangelio se refiere a los Apóstoles. Se trata, por tanto, de un término referido a cuantos seguimos a Jesús: no hay castas en la Iglesia cristiana, o al menos, no debiera haberlas.

\section{Características de este discipulado}

Una ruptura total con el pasado. Implica abandonar familia e intereses propios (Mc 1,16-20; 2,14; Lc 14,26), decir no a uno mismo (Lc 14,27), perder la autonomía económica y romper con los valores imperantes (Cf. Mc 10, 41-45). La llamada de Jesús pide y hace posible romper con el pasado a la vez que ofrece al discípulo/a un nuevo futuro.

Entrar en una relación de por vida con Jesús. El texto de Mc 3,14, "para que estuvieran con Él" nos da el sentido de discipulado. Esto incluye la participación en la incierta vida de Jesús, en su sufrimiento y muerte (Cf. Mc 10,39; 8,34). No se trata de repetir las doctrinas del Maestro a modo de imitación, ni de adherirse a Él de una manera intimista. El discípulo colabora día a día con Jesús en la venida del Reino.

Ser enviado en misión. El elemento crucial es la inclusión en el ministerio de Jesús. El discípulo es tan pronto llamado como enviado. En él coinciden desde el inicio.

La Iglesia es la "comunidad de los discípulos de Jesús". Esto exige, en expresión de Schillebeeckx, escribir el "quinto evangelio",

El discípulo participa en la incierta vida de Jesús, coloborando en la venida del Reino 
añadiendo con la propia historia los relatos de tantas vidas aparcadas fuera de la sociedad, e incluso de la comunidad cristiana.

\section{DISCÍPULOS COMO CIUDADANOS}

Hemos visto cómo nuestra identidad cristiana es un regalo del que nos hacemos conscientes por Jesús. De ahí que sólo podamos comprender esta identidad recibida mediante la actualización de la "historia" de Jesús y de la comunidad creyente, en nuestras propias vidas. Esta historia nuestra ha de ser analizada en función de nuestra relación con Dios, con nuestro prójimo, con el mundo y con nosotros mismos. Para ese análisis contamos con tres grandes criterios: fe, esperanza y amor.

\section{Perfil del discipulado}

Estas tres virtudes son el esquema básico donde se enraízan otras virtudes más específicas que nos dan el "perfil" del discipulado cristiano:

- La apertura a escuchar y responder a la llamada de Dios.

- La gratitud, como característica de nuestra relación con Dios. Gratitud que debería afectar al resto de nuestras relaciones (con nosotros mismos, con los otros y con el entorno) y que se actualiza en la alabanza.

- Compasión, perdón y justicia, como las virtudes básicas de nuestra relación con el prójimo. La misericordia y fidelidad de Dios, la justicia "parcial" de Dios en favor del huérfano y de la viuda, son el paradigma del modo cristiano de relación con el otro. La relación intratrinitaria también nos enseña a basar nuestras relaciones en la reciprocidad, no en la necesidad o el dominio. Por último, la universalidad de la voluntad divina de salvación empuja a romper las fronteras sociológicas de la Iglesia.

La solidaridad en el uso compartido de los recursos naturales, que

El discipulo lleva a plenitud lo que significaser humano son regalo de Dios para toda la humanidad, la de hoy y la del futuro.

- Un uso creativo de los recursos personales como modo de hacerse plenamente humano. Por ello, el discípulo lleva a su plenitud lo que significa ser humano.

La formación de una persona con estas características es la tarea de la comunidad cristiana. Para ello, ésta se funda en la memoria viva 
de Jesucristo, a través de palabras y hechos de salvación. En este sentido, la narrativa de Jesús se re-actualiza por medio de la comunidad y, al hacerlo, modela el carácter de los cristianos.

La comunidad de discípulos de Jesús tiene un doble objetivo: estar con Él y predicar la Buena Noticia. Restringir nuestra concepción -personal y comunitaria- del discipulado al "estar con Él" (vida intraeclesial), lleva al aislamiento y rechazo sectario del mundo. Limitarse a la misión conlleva la devaluación de la mediación comunitaria.

\section{DISCÍPULOS: CIUDADANOS Y FORASTEROS}

Al analizar este tema, no podemos olvidar el trasfondo escatológico que impregna todo el N.T.: el final de un tiempo caduco y el inicio de un tiempo nuevo, el del Reinado de Dios. Desde esta perspectiva, lo mejor que se puede decir del poder del Estado y de la ciudadanía es que, aunque son meramente provisionales, pueden ser considerados como un instrumento al servicio de la voluntad de Dios. La distancia crítica que se observa en los textos neotestamentarios responde a esta tensión entre el "ya" del tiempo de Dios, iniciado en Cristo, que relativiza absolutamente la estructura social, y el "todavía no" de la espera al triunfo definitivo de Cristo.

Las "estructuras" no son exaltadas, mucho menos legitimadas como reflejo del orden eterno de Dios; el orden existente ha de ser reorientado. De este modo, la "nueva secta" de los cristianos que no tenía un ethos cultural propio, fue capaz de asumir lo mejor de su cultura circundante y subordinarlo al "Señor".

Según el teólogo estadounidense Stanley Hauerwas, "la Iglesia no ha de preocuparse de si está o no en el mundo; la única preocupación es cómo estar en el mundo, de qué forma y con qué objetivo ${ }^{14 "}$ ". Ese "cómo" de la presencia eclesial en el mundo se debate entre dos extremos: desde el polo sectario, que reclama una mayor distancia crítica y aislamiento de las estructuras sociales, hasta la inculturación total, que

Preocuparse de cómo estar en el mundo

14 HAUERWAS, Stanley and WILLIMON, William H. Resident Aliens: Life in the Christian Colony. Nashville: Abingdon Press, 1994, p. 48. Hauerwas es uno de los teólogos "comunitaristas" de Estados Unidos, sus escritos tienen cierto talante sectario, pero sus propuestas y preguntas son siempre sugerentes, especialmente en la reivindicación de la comunidad cristiana y su identidad. 
deja lo cristiano reducido al ámbito de lo privado (actitud muy presente en el ambiente secularizado del catolicismo "progre" español).

Aunque un estilo de Iglesia "confesante", crítica radicalmente con los poderes y estructuras del sistema, nos resulta muy atractiva, no podemos olvidar el papel que la razón y la cultura desempeñan en el desarrollo humano ( $\mathrm{y}$, por tanto, cristiano) de la persona. Si queremos transmitir la Buena Noticia al mundo, no podemos romper los canales de comunicación que nos ligan con él. También, hemos de reconocer que Dios trabaja no sólo dentro de la comunidad eclesial sino en todo lugar.

Se requiere, por tanto, una actitud humilde que sepa reconocer las contribuciones de la cultura y la sociedad secular a la comprensión y praxis cristiana de la vida.

La Iglesia ha defendido, históricamente, su derecho y obligación a transformar el mundo y se ha opuesto al abandono sectario del mismo. De ahí, su lucha por la libertad de "ejercer su misión entre los hombres sin traba alguna y dar su juicio moral, incluso sobre materias referentes al orden político cuando lo exijan los derechos fundamentales de la persona" (Gaudium et Spes, 76).

La pregunta sobre el cómo de la relación Iglesia-mundo sigue abierta; no hay una respuesta sencilla y universal. La perspectiva escatológica nos obliga a vivir en una perpetua tensión entre sectarismo y aculturación (pérdida de identidad en el proceso de inculturación). De hecho, silenciar la crítica que viene de los movimientos proféticos

Ser ciudadano, sabiéndose forasteros podría llevar a la Iglesia a ligarse excesivamente a los poderes políticos. Pero, subrayar en exceso la especificidad de la vida cristiana haría imposible la misión de evangelizar la cultura y el mundo. La tensión nos obliga a ser ciudadanos sin perder la distancia del que se sabe forastero (1 Pe 2,11).

\section{VOLUNTARIADO SOCIAL COMO CIUDADANÍA CRIS- TIANA}

A la vista del capítulo anterior, podemos afirmar que, si bien existe un modo plural de ser cristiano/a en el mundo, como cristianos estamos llamados a vivir en nuestra sociedad ejerciendo la ciudadanía con una radicalidad especial. Esta radicalidad resulta de aplicar a nuestros 
deberes ciudadanos los criterios que hemos visto al hablar de discipulado.

He defendido que el voluntariado social es uno de los medios privilegiados para vivir en la práctica ese modo cristiano de ser ciudadano. En la tensión entre ciudadanía y discipulado, el voluntariado social permite "vivir en la frontera", participar de ambas identidades sin merma ni confusión de las mismas.

En este capítulo, analizaremos en qué se fundamenta el voluntariado social desde la fe en Jesús el Cristo, qué contribuciones aporta el discipulado a la acción voluntaria y cómo se caracterizaría la ciudadanía cristiana.

\section{VOLUNTARIADO SOCIAL COMO TAREA CRISTIANA}

Existen dos fuentes principales para comprender el voluntariado como tarea cristiana.

a) La preocupación por los pobres a lo largo de la Escritura. Preocupación que nos habla de la misma identidad divina. Nuestro Dios es un Dios relacional y en Él la relación se basa en el amor, no en el dominio, ni en la exclusión. Así, desde la Antigua Alianza de Yahvé con Israel en el Sinaí, la relación con Dios pasa por el cuidado de aque1los que no pueden defenderse a sí mismos, la viuda y el huérfano (Ex 22,21). El Dios “compasivo" del A.T. (Ex 34,6) va más allá de la Ley y la justicia. El lenguaje de Dios no se basa en derechos, sino en la misericordia y compasión.

b) El concepto de discipulado, analizado anteriormente. El mandato de amor al prójimo, junto con la explicación del significado de la palabra "prójimo" en el relato del buen samaritano (Lc 10,25-37) y, la propuesta de las bienaventuranzas, otorgan un lugar central al cuidado del otro en la vida del discípulo/a. De tal modo van unidos el amor a Dios y al prójimo que no cabe confesión de fe sin testimonio de amor y compasión por los demás (cf. Mt 25, parábola del Juicio final).

Es en el envío en misión donde encontramos la llamada a una acción voluntaria para el cristiano. Jesús, al enviar a sus discípulos a proclamar la Buena Noticia, les pide: "curad enfermos, resucitad muertos, limpiad leprosos, echad demonios. Gratis lo recibisteis, dadlo gratis" (Mt 10,8). De este modo, no cabe proclamación de la Palabra de

Preocupación por los pobres, basados en la compasión de Dios

Envío, raíz de la acción voluntaria 
Dios sin "prácticas del Reino15". Y las características de estas prácticas coinciden con las que vimos para el voluntariado social: gratuito, orientado al otro, dirigido a la inclusión en la comunidad.

Por tanto, el voluntariado social no es una opción libre para el

Voluntariado Social es una llamada para el cristiano cristiano; es una llamada, un mandato, una característica intrínseca de nuestro discipulado. Resulta imposible ser cristiano/a, pertenecer a la "comunidad de memoria" del amor y la entrega de Dios por la humanidad sin "darnos gratuitamente", al estilo de nuestro Dios y como respuesta agradecida a su iniciativa. Por ello, el obispo Echarren afirma que "todo cristiano, por el hecho de ser discípulo de Jesucristo, tiene que ser un voluntario social ${ }^{16 "}$.

\section{2. ¿EXISTE UN VOLUNTARIADO CRISTIANO?}

Un estudio sobre el voluntariado nos ofrece las siguientes características, relacionadas con la presencia cristiana:

a) La motivación religiosa es muy frecuente a la hora de dar cuenta del porqué de nuestra acción voluntaria. Esta motivación no aparece en solitario: los ideales de tipo religioso se mezclan con la autorrealización (p.ej., cruzar fronteras sociales, conocer nuevas personas, adquirir experiencia, etc.). No debemos engañarnos, la motivación religiosa no es incompatible con el individualismo ${ }^{17}$.

b) La Escritura nos provee de un lenguaje de compasión y apertura al otro, que tienen un papel vital a la hora de dar sentido a la experiencia de ayudar a los demás. Esto que puede parecer secundario no lo es en nuestra cultura utilitarista. ¿Cómo dar sentido a la impotencia e ineficacia vividas en el acompañamiento de un enfermo terminal? Es cierto que se intenta aplicar criterios económicos y utilitaristas a la acción voluntaria, pero el intento resulta caricaturesco en la mayoría de los casos. La alternativa no es "mercantilizar", ni "estatalizar" el len-

15 CATALÁ, Toni, op. cit. p. 15

16 ECHARREN, Ramón, El voluntariado social, aviso para creyentes. Santander. Sal Terrae, 1989. En Sal Terrae, 911, p.464

17 Cf. WUTHNOW, Robert. Acts of Compassion. Princeton University Press, 1991. esp. p. 121-190- Wuthnow ofrece un sugerente análisis del papel de la fe en la acción voluntaria. 
guaje del voluntariado, sino abrir brechas de relación compasiva y gratuita en una cultura necesitada de humanidad.

c) La pertenencia a una comunidad predispone al voluntariado en mayor medida que la sola fe. La comunidad cristiana evita que la acción voluntaria se convierta en justificación y legitimación del individualismo, aunque éste sea religioso. La comunidad acompaña al cristiano, le aporta una narrativa -la de Jesús- y una tradición hecha de lucha y esperanza y le predispone a un estilo radical de servicio. Es la comunidad cristiana la que puede ayudar a una reflexión crítica, desde los criterios de las Bienaventuranzas, sobre la auténtica compasión, solidaridad y justicia de nuestro altruismo.

Aún más: en un voluntariado que pretende la inclusión de quienes están al margen, es absolutamente necesaria la comunidad como vehículo de esta inclusión. Sólo si un grupo con identidad e historia propia -y conectado con la sociedad- avala la "admisión" de los excluidos será ésta posible.

d) Se da en nuestra cultura una batalla semántica entre el universo de significados que surgen de palabras como "justicia y solidaridad" frente al que responde a términos como "compasión y gratuidad". La teología feminista de los últimos años ha subrayado el papel central del amor y del caring (cuidado gratuito del otro) junto al de la justicia. Los defensores de la justicia temen que hablar de compasión y gratuidad sentimentalice y difumine la radicalidad del compromiso por el cambio de estructuras. Por contra, los defensores de la misericordia, la ternura y la compasión en la lucha por la justicia, recriminan a los anteriores su no implicación personal, su falta de sensibilidad para escuchar y dar protagonismo a las víctimas del sistema, su rigidez cuasiburocrática a la hora de trabajar con los excluidos... Ambos universos de significado nos son necesarios para comprender y dar sentido al voluntariado. La propuesta cristiana es avanzar en la implicación y relación directa. Ésta nos llevará a una radicalidad de nuestro análisis y a la utopía. Así, en palabras de J. Coleman, "si en cualquier estrategia de la teología cristiana se considera central la opción fundamental por los pobres, (esto) nos llevará más allá de las categorías de justicia, hacia las de solidaridad, comunidad en el sufrimiento y ágape ${ }^{18}$ ".

18 COLEMAN, John A. An American Strategic Theology. New York, Paulist Press, 1991.

La comunidad ayuda al sentido auténtico de la compasión 
Tal opción conlleva una ética de la solidaridad y diferencia, una nueva Iglesia entendida como comunidad de inclusión e integración y, finalmente, una nueva justicia, más honda y más humana.

Opción por los pobres, la contribución del discipulado a la ciudadanía

Como vimos en el primer capítulo, resulta difícil encajar la razonabilidad del "privilegio epistemológico de los pobres", así como la opción preferencial por los mismos. Esta dificultad desaparece (la de la razonabilidad teórica, no la de la vivencia práctica) al pensar nuestra vida en función del estilo de Jesús de Nazaret.

Esta opción explícitamente requerida, en primer lugar, en los Documentos de Medellín y Puebla y, posteriormente, confirmada en diversos documentos pontificios (Cf. Sollicitudo Rei Socialis, 47) tiene una larga historia en la reflexión social de la Iglesia. No es simplemente una cuestión ideológica, ni siquiera política. Se trata de un modo de vida que exige:

- implicación personal (estilo de vida, trabajo, ubicación social),

- análisis socio-político,

- asunción de compromisos concretos,

- y, por supuesto, conversión.

Esto implica un cambio radical en nuestra visión de la realidad e, incluso, de nuestra idea de justicia. Para ello, hemos de empezar por unir la conciencia histórica que emerge de las voces de los oprimidos junto con la interpretación de la Escritura, hecha desde los excluidos.

Además, una opción tal no puede quedar reducida a la inmediatez del encuentro personal. Exige, también, un trabajo estructural, con las mediaciones sociales, por el cambio social. Esto conllevará conflicto, tensiones, rechazos y descalificaciones. No es nuevo. Viene sucediendo en nuestra sociedad e Iglesia en las últimas décadas. Pero sí es una novedad la insistencia en la necesidad de un contacto directo con los excluidos y en una conversión personal que asuma la cultura y

Necesidad de una sociedad fraterna $y$ justa la cosmovisión de las capas últimas de la sociedad.

Ésta es la contribución del discipulado a la ciudadanía: fundamentar en la misma identidad humana la necesidad de una sociedad fraterna y justa. La novedad de esta ciudadanía estriba en su capacidad para unir la memoria peligrosa de Jesús a la memoria, también peli- 
grosa, de la larga historia de sufrimiento de la humanidad. Olvidar esta aportación es la mayor traición que, como cristianos, podemos hacer a la proclamación de la Buena Noticia. No todo voluntariado, al igual que no toda forma de ejercer nuestra ciudadanía, es cristiana. Por ello, para terminar nuestra reflexión hemos de apuntar en qué se concreta lo cristiano de nuestra acción voluntaria, de nuestro trabajo por una sociedad más justa y solidaria, desde la fe en Jesús, el ajusticiado en la cruz y vencedor de la muerte.

\section{CIUDADANÍA CRISTIANA}

La vida de Jesús, sus palabras y sus prácticas de justicia marcan el estilo cristiano de la solidaridad y del trabajo con y por los pobres; nos pide una implicación crítica en la sociedad. He propuesto la opción por los pobres como la contribución principal del discipulado a la ciudadanía. Esta contribución es doble. Supone colaborar con la voluntad Implicación crítica en la sociedad de justicia y compasión de nuestro Dios e impulsar una concepción comunitaria de la sociedad: una comprensión radical de los deberes ciudadanos que rompe con nuestro lenguaje de derechos adquiridos, proponiendo un lenguaje de compasión y justicia.

Para que nuestra ciudadanía -nuestra pertenencia y trabajo en la sociedad en que vivimos- sea cristiana, ha de ser crítica, utópica, radical y compasiva. Estos calificativos -aplicables también a la ciudadanía cristiana- nos servirán de criterios de evaluación de la radicalidad de nuestro voluntariado.

\subsection{Ciudadanos críticos}

Nuestra crítica nace de la tensión entre el discipulado y la ciudadanía. Ya nos hemos referido a la distancia crítica que, como "miembros del cuerpo de Cristo" hemos de mantener frente a cualquier estructura social. Pero, distancia crítica implica compromiso con las mismas estructuras y mediaciones humanas para su mejora.

No podemos ser sectarios. No fue ese el estilo de Jesús. La misma organización de la comunidad cristiana ha de lidiar con otras organizaciones sociales, colaborar con ellas y/o pelear en su contra, para vivir auténticamente su identidad cristiana. 
Respeto a la pluralidad. Diá$\log o y$ colaboración

Complementariedad no contraposición
En esa relación conflictiva, no se puede despreciar la legítima autonomía del ideal ciudadano. El respeto a la pluralidad humana y al derecho de todos a construir la sociedad humana, nos obliga a la colaboración, al diálogo, y a aceptar las contribuciones que la ciudadanía secular aporta a nuestro estilo de vida. Las podemos resumir en:

- ampliación del campo de acción de la solidaridad cristiana más allá de las fronteras sociológicas de la Iglesia frente a tentaciones sectarias y de "puertas cerradas" (nuestros pobres, nuestros marginados, nuestros compromisos... son expresiones, aún, frecuentes en ambientes cristianos);

- exigencia de una actitud más humilde en nuestro trabajo rechazando la utilización prepotente del poder institucional;

- puesta a prueba de la reivindicación cristiana de liberación en este mundo, por la acción de la Gracia de Dios.

Si no queremos que esta proclamación sea vacía, es preciso que aportemos alternativas que dignifiquen la vida humana de los oprimidos y marginados.

En el ámbito del voluntariado este respeto a nuestra doble identidad implica, en términos de García Roca, un espíritu de complementariedad frente a uno de contraposición, colonización o mera yuxtaposición ${ }^{19}$. Una de las claves del futuro de la acción voluntaria cristiana se juega en nuestra capacidad de complementariedad "crítica" con otras organizaciones sociales y con la Administración del Estado. Si dejamos las políticas sociales en manos de otros, si nos consideramos mejores (más compasivos, más radicales, etc) y despreciamos la experiencia y capacidad de gestión del sector estatal... habremos perdido, de nuevo, la posibilidad de generar una sociedad distinta y, con ello, habremos traicionado, una vez más, a quienes decíamos querer servir: los excluidos.

\subsection{Ciudadanos utópicos}

Como cristianos somos ciudadanos de "dos ciudades"(Gaudium et Spes, 43). Esto exige que seamos "bilingües", es decir, capaces de hablar y vivir el lenguaje bíblico con su carga de compasión y radica-

19 GARCÍA ROCA, Joaquín. Público y privado en la acción social. Del Estado del Bienestar al Estado Social. Madrid. Popular, 1992. (Trabajo Social, 18), p. 62. 
lidad, de sufrimiento histórico y esperanza, y el lenguaje de nuestra cultura con su modo de pensar crítico y racional. ¿De qué sirven nuestros discursos radicales si no admiten mediación cultural y, por tanto, son incomprensibles? Muchas de nuestras argumentaciones y explicaciones de la radicalidad cristiana chocan con el bloqueo racional de nuestros contemporáneos.

La necesaria "traducción" al lenguaje social de nuestra visión utópica no puede hacernos perder la radicalidad de nuestra esperanza. De hecho, el discipulado añade a la política una visión utópica que se enraíza en el Evangelio como promesa, juicio y vocación. Promesa de una sociedad nueva, justa y solidaria y que, aunque empujada por todos nosotros, 1legará de manos de Dios. Juicio de un mundo que margina a sus gentes y les niega la dignidad y libertad de hijos de Dios. Vocación o llamada a la construcción de un orden nuevo en el que sea posible proclamar la Buena Noticia a toda la humanidad.

La utopía cristiana para la sociedad es comunitarista. Los principios expuestos en la Doctrina Social de la Iglesia, el de "subsidiariedad", y su complementario de "socialización", unidos al concepto de "justicia como participación" y al de la "opción por los pobres", ofrecen una estructura de análisis crítico de la sociedad y guían a la comunidad cristiana en la búsqueda de un orden social justo y solidario.

La progresiva complejidad de los "mundos vitales" y de las relaciones entre los agentes sociales, obliga a seguir analizando e interviniendo en el entramado social. Aquí tiene un papel crucial el voluntariado social: aporta datos de las nuevas formas de opresión y marginación, y mantiene el horizonte utópico gracias a un continuado análisis socio-político.

\subsection{Ciudadanos radicales}

Nuestra radicalidad no es otra que la de la entrega de Jesús por toda la humanidad. En su asumir todo el dolor de la humanidad y, en la respuesta de aceptación del Padre, está la clave del porqué los cristianos creemos que es necesario estar cerca, incluidos, en los sectores de población que continúan "crucificados". Hemos de cuidar que esta cercanía radical a las víctimas no nos haga "apologetas del sufrimiento". No valoramos el dolor en sí; nuestro acercamiento no ha de ser

Estar incluidos en los sectores de población que continúan "crucificados" 
culpable, sino liberador, portador de esperanza, abierto a descubrir dignidad humana donde la sociedad la niega.

La invitación es a una ciudadanía mucho más comprometida que - la que ofrece nuestra democracia formal; más encarnada que la de un cierto humanismo preocupado sólo por la fraternidad y no por la revolución que aquí (y en los documentos pontificios) se pide: lograr la inclusión de todos y que toda la sociedad viva y pelee unida por el Bien Común. Poco más cabe decir de este aspecto, basta leer de nuevo el apartado del voluntariado cristiano. Si nos tomamos en serio la opción

Nuestra visión de la realidad se hace "mestiza" por los pobres, si nuestro mundo de amistad y relación "incluye" a los, hasta ahora, excluidos, si nuestra visión de la realidad se hace "mestiza", aceptando sus puntos de vista y sus herramientas culturales de análisis... si, en definitiva seguimos leyendo Mt 25 y al llegar a "lo que hicisteis por uno de estos pequeños"... nuestras entrañas se conmueven... nuestra ciudadanía será cristianamente radical sin remedio.

\subsection{Ciudadanos servidores}

Todo lo anterior es posible, únicamente, desde el ejemplo de Jesús en el lavatorio de los pies (Jn 13,1-17). Nuestro Dios se hace "servidor" nuestro. Y es que, a los pies del otro, la vida tiene un significado distinto. Cuando Jesús se puso a los pies de sus discípulos sabía que su fin estaba cerca: "había amado a los suyos que vivían en el mundo y los amó hasta el extremo" (Jn 13,1). Ese es el contexto existencial de Jesús, el amor, desde el que comprender el resto de aquel encuentro último.

$\mathrm{Al}$ acercarnos como voluntarios a ofrecer parte de nuestro tiempo, no intuimos los cambios que se van a producir en nosotros. De la compasión y el encuentro con el que sufre pasamos a la rabia e indignación por su sufrimiento injusto. Ello nos obliga a analizar y tratar de atajar las causas del mismo. En ello se nos van energías y nos cambia la vida. Y, al final, aún habiendo aliviado sufrimiento, somos conscientes de que el mal sigue campando en nuestra sociedad. Por eso, si nos dejamos empapar, incluir en la narrativa de Jesús, ésta dará sentido a nuestra entrega gratuita, sostendrá las sucesivas crisis de desencanto por las que, inevitablemente, ha de pasar todo aquel que se compromete radicalmente. Además, tendremos una concepción distinta de 
la persona y de la sociedad que implique la visión desde los pobres y la lucha por una sociedad inclusiva.

Por último, es desde esa narrativa, desde la que nos adherimos a una tradición, a una comunidad. Ahí recibimos el impulso, la formación, el lenguaje, los valores para acercarnos radicalmente a la injusticia y luchar con ella al estilo de Jesús.

Una vez más, el voluntariado social, reforzado por el lenguaje y tradición de la comunidad creyente, ofrece un camino de integración de ambos universos: el de la justicia y el de la gratuidad, al implicar el compromiso personal con la lucha por la justicia social y el cambio de estructuras. Servicio directo, sí, pero enviados, también, a proclamar, a defender en la arena política, nuestra alternativa solidaria. La doble tarea de todo voluntario cristiano (implicación personal y denunciapropuesta) se hace de este modo "confesional", confesante de un Dios que ama sin condiciones y sin exclusiones. El amor -hecho de servicio, gratuidad, compasión, denuncia, análisis y propuesta- es pues el criterio último de nuestra acción voluntaria, de nuestra ciudadanía cristiana. Este principio provoca conflictos con la sociedad y con la misma Iglesia, pero es el que nos permite comprender el voluntariado social como discipulado cristiano, que no es otra cosa que actuar con justicia, amar con ternura, y caminar humildemente junto a nuestro Dios.

Voluntariado con la comunidad, camino de integración 


\section{APÉNDICE 1:}

UN RETO PARA EL VOLUNTARIADO: SU APORTACIÓN A OTRO MODELO DE SOCIEDAD

Extracto de: Víctor Renes, Panorama del voluntariado: elementos para una radiografía, Revista de estudios de Juventud (Ministerio de Asuntos sociales), diciembre 1989.

"El compromiso por el cambio es un axioma para el voluntariado. Un voluntariado conservador es una contradicción. El voluntariado nace porque ve disfunciones, necesidades insatisfechas, sufrimientos físicos y morales y decide intervenir para cambiar estas situaciones.

in Un voluntariado conservador es una contradicción

El problema es: ¿qué intenta modificar el voluntariado? ¿Hasta qué punto está dispuesto a volcarse sobre el cambio?" (G. Pasini). Debemos descubrir cómo un voluntariado puede constituir conciencia crítica y, por ello, producir cambios. Veamos el conjunto de valores que sostienen la intervención del voluntariado.

- El paso de una cultura de tipo elitista selectiva, en la que prevalecen las relaciones de fuerza,

... a una cultura comunitaria con la consecuente atención privilegiada a los más débiles.

- El paso del individualismo y del rechazo de los problemas de los débiles, cómo problemas "ajenos",

... a la corresponsabilidad en lo que respecta a las personas y en lo que respecta a la sociedad.

- El paso del hábito del anonimato

... a la búsqueda de relaciones personalizadas.

- El paso del hedonismo

... al sacrificio; el servicio a los pobres no es, por su naturaleza, agradable.

- El paso del consumismo y la categorización del "tener",

... al "ser" como referencia de una calidad de vida que reencuentra como tal la austeridad, testimoniada por muchísimas comunidades del voluntariado.

- El paso de la emotividad y de lo provisorio

... a la fidelidad y a la continuidad de las relaciones y del servicio. 
Estos valores serán un impulso para el cambio en la medida en que sean asumidos permanentemente por la persona y se reflejen, en consecuencia, en la vida cotidiana, en el compromiso político, etc.

El cambio puede venir también del contacto humano de los voluntarios con los pobres y marginados. Una relación humana bien conducida puede sacudir el pasotismo y la fatalidad, suscitar y movilizar energías facilitando un proceso de autonomía y liberación de las personas asistidas.

Otra contribución puede nacer del contacto con los profesionales de los servicios: con su testimonio les induce a verificar la validez de sus prestaciones y la humanización de las relaciones.

Estas aportaciones plantean también unos interrogantes. Es obvio que los voluntarios deben ser igualmente "modificados" por las personas a las que ayudan sobre la base de los valores de los cuales son portadores. De lo contrario no se produce una "relación" real de ayuda. La simple relación humanitaria puede atenuar el sufrimiento, pero no supone un cambio real en los derechos de los que las personas ayudadas no disfrutan.

La propia aportación al cambio de los voluntarios, hace inevitable la pregunta: ¿qué debe ser cambiado en la sociedad, en las instituciones, en los servicios, para que sean modificadas las condiciones de pobreza y marginación en una perspectiva promocional y liberadora? Es inevitable abordar el espacio de la presencia del voluntariado en el campo "social" y "político".

Un cambio en profundidad exige la aportación de todas las fuerzas culturales, sociales y políticas sin olvidar aquellas a las que la población ha confiado la gestión del bien común. Dentro de esas fuerzas, el voluntariado por su sensibilidad social y por su contacto cotidiano con los débiles, dispone de un potencial de cambio quizá insustituible.

En relación con su presencia en el campo "social", el objetivo central es que los problemas de pobreza y marginación lleguen a ser considerados y tratados como un problema de la propia sociedad, así como el de modificar la cultura dominante que se resigna a considerar esos problemas como componentes "físiológicos" del desarrollo social.

En relación con el campo "político", en síntesis se puede decir que la relación con las administraciones públicas se mueve sobre dos rieles complementarios: 
- El del estímulo y la denuncia contra incumplimientos, inoperancias, disfunciones, carencias legislativas.

- El de la colaboración activa, promoviendo iniciativas piloto de servicios y desarrollando una verdadera y adecuada colaboración concretada, en un equilibrio no siempre fácil entre el mantenimiento de una sustancial libertad de cara al poder y la demostración de una concreta voluntad de colaboración. 


\section{APÉNDICE 2:}

\section{LA IDENTIDAD DEL VOLUNTARIADO: DECÁLOGO PARA UNA BÚSQUEDA}

Tomado de Joaquín García Roca, Solidaridad y voluntariado (Ed. Sal Terrae, 1994), libro que recomendamos muy vivamente, y que recomienda por sí mismo el éxito editorial y de crítica de que ha sido objeto. García Roca pretende en primer lugar realizar una visita guiada por los territorios de la acción voluntaria y en este sentido posee un innegable interés sociológico. Sitúa al voluntario en un horizonte nuevo, abre ventanas y le da elementos críticos para poder entrar en este mundo, tan a menudo desconocido. El libro resulta guía y acompañamiento; además de alentar, da pautas para la reflexión y acción. Lo recomendamos y queremos transcribir el siguiente decálogo con que termina el libro.

El voluntariado necesita descubrir la complejidad de los procesos sociales; una idea simple es una idea simplificada. Los problemas sociales tienen la forma de la tela de araña: están tejidos por multitud de factores. Saber estar en una sociedad compleja disponiendo de una buena información es una cualidad esencial del voluntariado hoy.

El voluntariado sólo tiene sentido cuando no pierde de vista el horizonte de la emancipación. Es necesario darle ternura a un enfermo terminal o acoger a una persona que lucha contra su adicción, pero ello sólo merece la pena si es un paso más en la remoción de las causas de la marginalidad y del sufrimiento innecesario.

La acción voluntaria sólo tiene calidad ética cuando es la opción libre de un sujeto en el interior de una triple aspiración: la estima de sí mismo, la solidaridad con los demás y el compromiso por una sociedad justa.

El voluntariado no es una coartada para desmantelar los compromisos del Estado, sino más bien para reclamarlos. Si su presencia es, en algún momento, un pretexto para que la Administración se retire o reduzca sus esfuerzos, el voluntariado ha entrado en zona de peligro.

La acción voluntaria es como una orquesta: lo importante es que suene bien; importa poco si la flauta es de madera o de metal, si es propiedad de éste o de aquél. A la orquesta debemos exigirle coordinación, 
coherencia y concentración de esfuerzos. El voluntario es siempre un "co-équipier". La fragmentación no conduce a nada, y en el equipo cada cual juega en su propio lugar colaborando con el resto en función de la partida.

La acción voluntaria ha de tener competencia humana y calidad técnica. Con el amor no basta; si, por ignorancia o por incompetencia, hiciéramos sufrir a una persona frágil, aunque fuera con la mejor intención, sólo lograríamos aumentar su impotencia y su marginalidad.

El voluntariado debe ganar espacios en las clases populares. No puede ser una institución que interese sólo a las clases medias ni a aquellos a quienes les sobra tiempo; más bien responde al ejercicio de la ciudadanía que se responsabiliza de los asuntos que afectan a todos.

El voluntariado estima al profesional de la acción social y buscará siempre la complementariedad; pero, por lo mismo, no se convierte en auxiliar ni en correa de transmisión, sino que defiende el espacio de libertad que le es propio.

El voluntariado necesita hoy disciplinar su acción. Las mejores iniciativas se pierden por incapacidad de someterlas a un programa, a unos objetivos, a un método, a unos plazos, a una dedicación seria, a una evaluación. La buena intención es un camino viable si hay disciplina; si no la hay, es un fracaso. El voluntario rehuye las palabras vanas y se acerca a los gestos eficaces. Es importante servirse de palabras justas y de expresiones exactas.

La acción voluntaria requiere reciprocidad: no se orienta simplemente a la asistencia del otro, sino al crecimiento de ambos, aun cuando sean diferentes sus contribuciones. La estima del otro no sólo exige la acogida, sino que además espera una respuesta análoga. 